\title{
Modeling and Simulation of Collaborative Dispatching of Disaster Relief Materials Based on Urgency
}

\author{
Gaofeng Guan $\mathbb{D}^{1,2}$ Zijun Lin, ${ }^{2}$ Yu Gong $\mathbb{D}^{3},{ }^{3}$ and Zhijuan Jiang ${ }^{4}$ \\ ${ }^{1}$ School of Economics and Management, Zhejiang University of Science and Technology, Hangzhou 310023, China \\ ${ }^{2}$ School of Economics and Management, Southwest Jiaotong University, Chengdu 610031, China \\ ${ }^{3}$ Southampton Business School, University of Southampton, Southampton SO17 1BJ, UK \\ ${ }^{4}$ School of Management Science and Engineering, Nanjing University of Information Science and Technology, \\ Nanjing 210044, China \\ Correspondence should be addressed to Yu Gong; y.gong@soton.ac.uk
}

Received 5 April 2020; Revised 20 June 2020; Accepted 27 June 2020; Published 10 August 2020

Academic Editor: Alessio Ishizaka

Copyright (c) 2020 Gaofeng Guan et al. This is an open access article distributed under the Creative Commons Attribution License, which permits unrestricted use, distribution, and reproduction in any medium, provided the original work is properly cited.

In order to address the lack of collaborative decision and failure to notice the emergency and fairness of relief after disasters have occurred, a collaborative decision-making system for emergency relief materials dispatching is established. According to the forecast of the demand for postdisaster relief materials, the entropy weight-TOPSIS method is applied to measure the urgency of the disaster area; then, a "Hub-and-Spoke" dispatching network is constructed. In this paper, a multiobjective collaborative relief material dispatching model is built, which has great performance in terms of minimal distribution cost and maximal fairness, and the objective of fairness requires minimizing the penalty cost caused by unsatisfied demands. Based on the urgency of demand points, the simulated annealing algorithm is designed to solve the Pareto disaggregation of multiobjective optimization model. The performance of the model is verified with the case of Wenchuan Earthquake. The results indicate that if the fair distribution of supplies is emphasized, it will increase the number of rescue vehicles and the number of distribution batches. On the other hand, a variety of relief material dispatching plans can be provided based on calculation of the Pareto front for policy-makers.

\section{Introduction}

Frequent large-scale natural disasters, such as earthquakes, floods, ice, and snow disasters, have caused serious damage to and far-reaching impact on modern society. According to the China National Ministry of Emergency Management and the National Disaster Reduction Commission, 130 million Chinese people were affected by natural disasters in 2018, 589 of whom died in these disasters [1]. Taking earthquakes, for example, in 2018, 3,068 people were killed by earthquakes in the world. After large-scale disasters have occurred, rapid and effective dispatching of emergency materials is a key factor in the efforts to save people's lives and ensure smooth progress of relief work. However, in practical relief activities, due to lack of collaborative dispatching of emergency materials, it tends to result in unreasonable distribution of emergency materials and chaotic distribution. During the dispatching of relief materials, both the maximal fair distribution for affected areas and the minimal cost of logistics service providers need to be considered. Therefore, the decision makers should find a solution to address these problems, and collaborative distribution of relief materials is a possible solution because the complexity and multiple stages of relief activity determine the necessity of collaboration during relief process.

At present, scholars specialized at operations management have conducted extensive research studies in a humanitarian relief setting [2]. Related research studies on the dispatching of disaster relief materials focus on various aspects, including forecasting of emergency supplies demand [3-5], site selection [6-8], and resources optimization [9-11]. For complex relief supply collaboration among multiple organizations, timely distribution of emergency materials is an important objective. Therefore, the emergency material scheduling optimization model generally aims to achieve the objective of the shortest delivery time. 
Wex et al. [12] constructed an emergency material distribution model with the objective of minimizing the total transport time. By studying the scheduling model of humanitarian emergency supplies, Hamedi et al. [13] aimed at realizing the shortest delivery time, and they adopted genetic algorithm based on heuristic to achieve this goal. Ahmadi et al. [14] proposed a multidepot location routing model, and this model involves the use of multiple vehicles and standard relief time constraints. Bodaghi et al. [15] presented a biobjective mixed integer programming method that can help minimize the total weighted time of completion of the demand points. To minimize of the overall arrival time of relief vehicles, Sabouhi et al. [16] proposed a mixed integer linear programming model for routing and scheduling of vehicles. Ghaffari et al. [17] proposed a scheduling approach integrating distribution, production, and transportation in a capacitated supply chain network, which can minimize the total weighted completion time.

Meanwhile, some scholars investigated the issue of emergency supplies dispatching and transportation based on the consideration of fairness or the highest satisfaction. Sheu [18] proposed a hybrid fuzzy clustering method based on a three-tiered emergency logistics hybrid dispatching framework, in which the relief materials dispatching model is divided into three layers, with the objective of maximizing the relief rate. Pang et al. [19] established an emergency supplies dispatching and transportation optimization model based on the principle of fairness, with the goal of minimizing the system losses. Song et al. [20] constructed an emergency supplies scheduling model which involves multiple emergency response points, multiple relief points, and multiple stages. Zheng et al. [21] established a bilevel dynamic planning model with the goal to maximally satisfy the material delivery time. Mishra et al. [22] employed two basic round-robin-based greedy search algorithms and proposed an optimized algorithm for fair distribution of relief materials. The fairness was measured based on minimal absolute standard deviation between demand and supply at the disaster depots. Das [23] identified the factors that affected the demand for disaster relief supplies based on a warehouse location model aimed at maximum satisfaction which was constructed. Xue and Feng [24] established an emergency supplies dispatching optimization model with the goal of minimizing the weighted arrival time of disutility under concern of fairness. Chen and Zhao [25] established a dual-objective optimization model based on the consideration of fair dispatching of materials among regions. The objective function of the model is employed to maximize the amount of material supply in the area and to minimize the maximum transit time. Zhang et al. [26] studied the Talmud dispatching model, proportional dispatching model, and Shapley value dispatching model for investigation of the fair dispatching of emergency supplies. Afterwards, Feng et al. [27] established a multicycle emergency supplies batch delivery model that combines the goals of both efficiency and fairness by considering classification and batch delivery of emergency supplies.

The application of collaboration in relief supply chain has received increased attention recently [28-30].
Collaboration can realize timely supply of humanitarian aids and improve the overall response efficiency [31]. As the big data and block chain technologies are gaining popularity, understanding of their analytic process enables trust and collaboration, which is a promising research area [32-37]. Altay et al. [38] examined the effects of supply chain agility and supply chain resilience on performance under the moderating effect of organizational culture. They had built conceptualized theoretical models for humanitarian supply chain. Lei et al. [39] proposed a resilient scheme for disaster recovery logistics to cooptimize the restoration of distribution system based on the dispatch of repair crews and mobile power sources. A novel cooptimization model is formulated to route repair crews and mobile power sources in the transportation network.

The main literature studies of the relief material distribution optimization models are listed in Table 1. However, these studies only highlight the importance of minimum time or maximum satisfaction/fairness. Most literature studies focus on the aspect of rescue time, providing relief at any cost. The distribution of relief supplies needs the collaboration among various subjects. Better cooperation between logistics service providers and relief organizations under the coordination committee is an important factor to determine the relief sustainability. This paper aims to establish a collaborative decision-making system for dispatching emergency relief materials, and the relief material dispatching model is built, which can achieve not only minimal distribution cost but also minimum penalty cost. The innovation of this model lies in consideration of the objectives of both minimum cost and maximum fairness.

We aim to further investigate the following aspects: (1) the dispatching and transport of emergency relief materials are associated with each other, which requires collaboration between them, but these two issues are often studied as separate topics in most literatures, lacking systematic consideration of the synergism between these two aspects; (2) in view of the serious shortage of relief materials in the early stage after the earthquake, less attention is paid to the difference among the affected areas in terms of relief urgency; (3) a collaborative decision-making system among the relief subjects has not been established yet. For this reason, with large-scale earthquake relief as a practical case, this work investigates the collaborative optimization of the dispatching of emergency relief materials under the emergency relief command system based on the actual situations of severe shortage of relief materials in the early stage after large-scale natural disasters.

The major contribution of this paper is that a new collaborative system for material dispatching is constructed. The entropy weight-TOPSIS (Technique for Order Preference by Similarity to an Ideal Solution) method is applied to measure the urgency of the disaster-hit area. Based on the urgency index of relief, the "hub-spoke" collaborative material dispatching network is built. The innovation of this paper is to combine the two aspects of reducing cost and achieving fairness in distribution. Simulated annealing algorithm is designed to solve the Pareto disaggregation of multiobjective optimization model. The Pareto optimal solution can provide 
TABLE1: Comparison of literature studies on relief materials distribution optimization model.

\begin{tabular}{lccc}
\hline Literature & Model objective & $\begin{array}{c}\text { Constraints } \\
\text { Transport } \\
\text { mode }\end{array}$ & Uncertain \\
\hline Wex et al. [12] & Minimum time & - & Yes \\
Hamedi et al. [13] & Minimum time & $\begin{array}{c}\text { Multiple } \\
\text { Ahmadi et al. [14] }\end{array}$ & Minimum time \\
Bodaghi et al. [15] & Minimum time & Single & Yes \\
Lei et al. [39] & Minimum time & Single & Yes \\
Sabouhi et al. [16] & Minimum time & - & Yes \\
Ghaffari et al. [17] & $\begin{array}{c}\text { Minimum time } \\
\text { Maximum }\end{array}$ & Single & Yes \\
Sheu [18] & $\begin{array}{c}\text { satisfaction } \\
\text { Maximum } \\
\text { fairness }\end{array}$ & Single & Yes \\
Pang et al. [19] & $\begin{array}{c}\text { Maximum } \\
\text { satisfaction } \\
\text { Song et al. [20] }\end{array}$ & Multiple & - \\
Zheng et al. [21] & $\begin{array}{c}\text { Maximum } \\
\text { satisfaction } \\
\text { Maximum } \\
\text { fairness }\end{array}$ & Single & Yes \\
Mishra et al. [22] & Single & Yes \\
& Maximum & Single & Yes \\
Das [23] & satisfaction & &
\end{tabular}

a variety of relief materials dispatching plan for policy-makers. The remainder of the paper is organized as follows. Section 2 introduces the components of collaborative decision-making system for dispatching of emergency relief materials. In Section 3, the optimization model of collaborative decisionmaking for emergency relief materials dispatching is depicted. Section 4 presents the simulation of collaborative dispatching of emergency relief materials. Further discussion and conclusion are provided in Section 5.

\section{Components of Collaborative Decision- Making System for Emergency Relief Material Dispatching}

After the occurrence of disasters, the supply and demand of relief materials are seriously unbalanced. For example, after Wenchuan Earthquake occurred, Chengdu received relief materials worth up to 110 million yuan, mainly in the form of 3 million pieces of clothing. At the same time, the massive inflow of international relief materials caused bottleneck in dispatching materials to regions in demand. Therefore, the material dispatching in emergency relief supply chain is in urgent need for collaboration among various parties, such as the relief organizations and logistics service providers. According to the stakeholder theory, a collaborative system for material dispatching in relief supply chain is constructed.

\subsection{Collaborative Subjects for Relief Material Dispatching.} The collaboration of relief material dispatching is a process in which the relief materials are quickly delivered to the disaster-hit areas based on the forecasting of materials demand, and such information is provided by the relief organizations and logistics service providers under the joint efforts of Coordination Committee and the sites with material demand in the areas struck by disaster. According to the stakeholder theory proposed by Kovács and Spens [40] for emergency relief supply chain, the emergency relief participants involve multiple stakeholders. As shown in Figure 1, they mainly include the relief organizations, logistics service providers, dispatching hubs (or demand sites in the disaster area), and relief coordinators. These stakeholders constitute the subjects of the collaborative dispatching of emergency relief materials. Bealt et al. [41] explored the collaborative relationships between logistics service providers and humanitarian organizations during disaster relief operations. After large-scale natural disasters, a large number of relief materials are donated to the relief organizations voluntarily, and some of the donors may try to gain social reputation and improve their social image. In contrast, relief organizations hope to get more money from the trust of the donors to help a large number of the affected people, and their activities run through the entire relief process.

Logistics service providers generally follow the code of conduct for commercial logistics, and they hope to obtain maximum profit, reduce the waiting time, and minimize the total logistics cost. In emergency relief operation, they more consider the social benefits of relief and provide relief logistics services free of charge to improve their social reputation. However, the logistics service providers also need to face the limitations of vehicle transport capacity and working time during the relief process.

The dispatching hub is responsible for forecasting the demands in affected areas, ordering and receiving relief materials, and delivering materials to the affected sites. The dispatching hub hopes to get more relief materials for the sites with demand in affected area, so it may show certain egoistic behavior.

Finally, the relief coordinator (normally, the Coordination Committee) is responsible for coordination during the whole emergency relief process, and such coordinator may be the emergency coordination affairs office. How to achieve cooperation among stakeholders and implement collaborative dispatching of relief materials is an important factor that determines successful emergency relief.

\subsection{Materials Dispatching Process in Relief Supply Chain.} For the dispatching process, Vanajakumari et al. [42] proposed a schematic representation of the relief supply chain, and the emergency relief materials are from the strategic distribution centers, passing Level-1 hubs (Prestaging Areas) and Level-2 hubs (Staging Areas) and reaching Level-3 hubs (Points of Distribution), which forms a relief hub-network. As shown in Figure 2, the Level-3 Hub is close to the affected area, so it is responsible for estimation of the relief materials demand, reasonable dispatching of vehicles among the dispatching hubs, and dispatching of the relief materials to the affected areas.

The strategic distribution centers are at fixed locations. For example, World Vision International has prepositioned inventory at three locations in the world: Colorado (USA), Brindisi (Italy), and Hanover (Germany). Similarly, Federal 


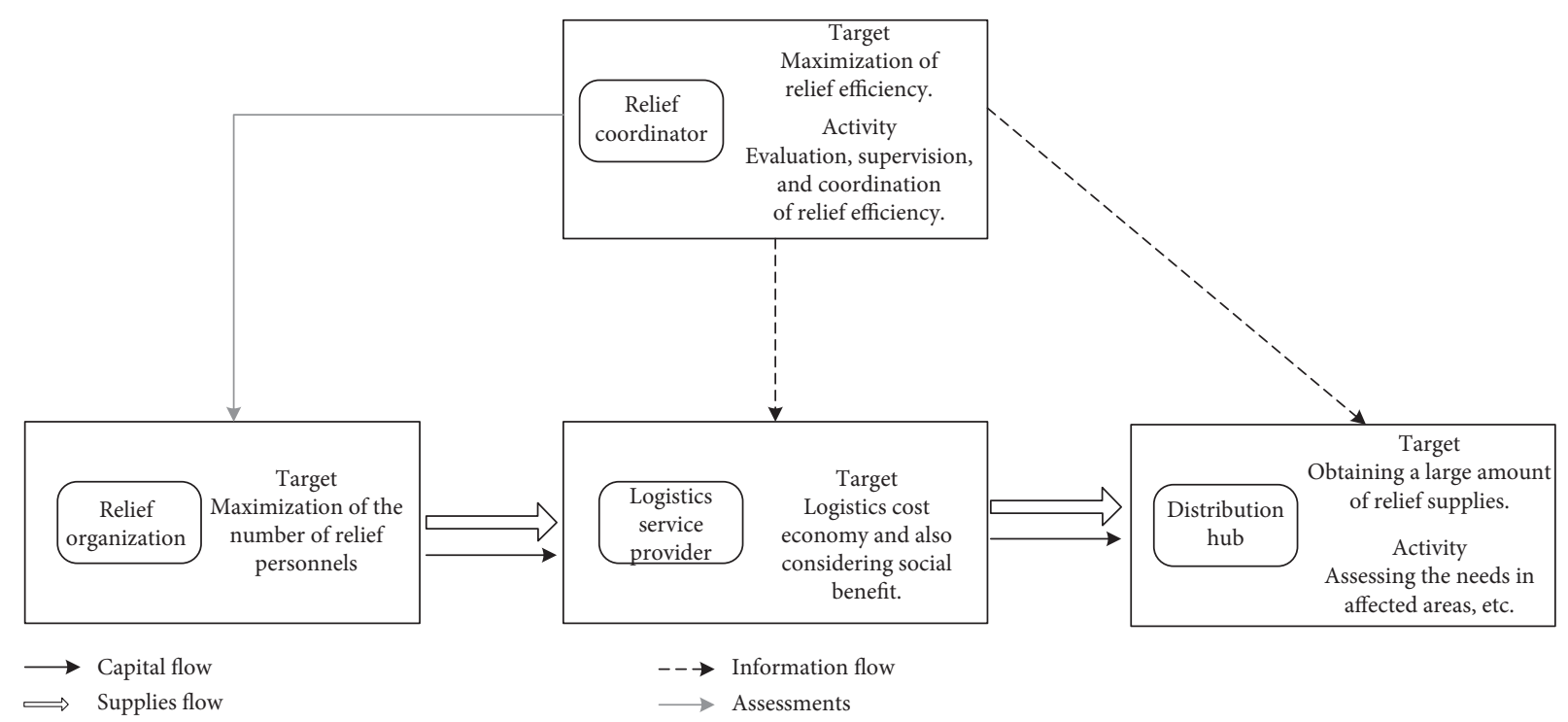

FIGURE 1: Stakeholders in collaborative dispatching of relief materials (adapted from Kovács and Spens [40]).

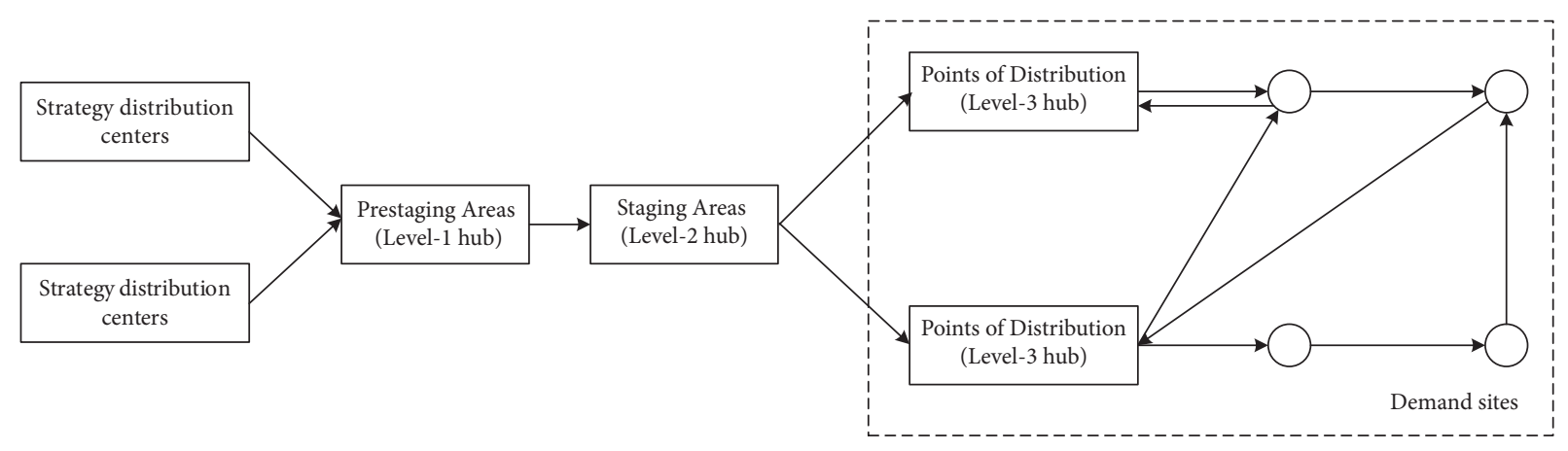

FIGURE 2: Flow chart of relief material dispatching.

Emergency Management Agency has nine Distribution Centers. Level-1 hubs (Prestaging Areas): the inventory is transported from the strategy distribution centers to a Level1 hub. The purpose of the Prestaging Area is to enhance the ability of aid agencies of quickly moving needed supplies. Level-2 hubs (Staging Areas): the Level-2 hubs are also temporary locations. Staging Areas are preidentified by the federal, state, or county governments before the disaster. Once the disaster strikes, the Prestaging Areas are selected and established at the preidentified locations, and then inventories are moved from the prestaging area to the stating areas. Level-3 hubs (Points of Distribution): finally, the aid is distributed to the affected people at the Points of Distribution. The selected Points of Distribution are close to the Staging Areas for fast access. After the affected area sends related demand information to Level-3 hub by relief request, Level-3 hub would reasonably allocate the relief materials to the demand sites.

2.3. Collaborative System for Material Dispatching in Relief Supply Chain. As shown in Figure 3, the logistics service providers undertake related logistics services, such as transportation and dispatching of relief materials. The Coordination Committee is responsible for the coordination between Level-3 hub relief organizations and logistics service providers in the dispatching of emergency relief materials. The relief organizations cooperate with logistics service providers by signing service agreements and submitting the vehicle arrangement plan to the Coordination Committee, so a similar "principalagent" relationship can be formed between the relief organizations and the Coordination Committee. The relief organizations submit the material plan to the Coordination Committee, which will then return the solution to the relief organizations. Finally, the relief organizations evaluate the performance of collaborative dispatching in relief supply chain based on relief emergency degree. The hypothesis that no information exchange is present between the demand subjects in the affected area could reduce the complexity of the model established hereinafter and restrict the flow of relief materials between the demand sites, thus achieving the best emergency relief effect. 


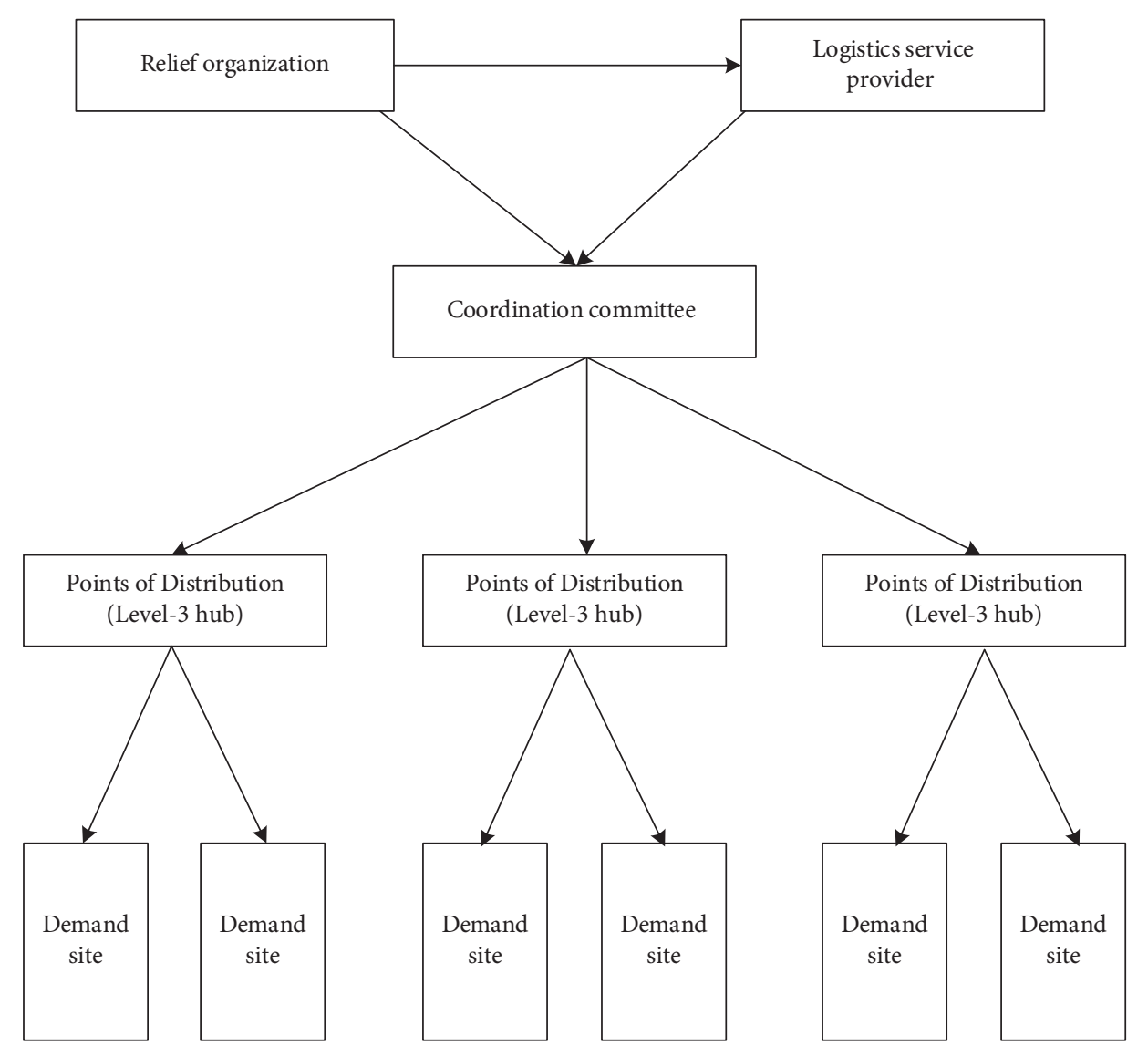

Figure 3: Collaborative system for material dispatching.

The relationship between various relief subjects essentially consists of the longitudinal coordination and lateral collaboration based on the information exchange between Coordination Committee, relief organizations, and logistics service providers, as well as Level-3 hub's material demand forecasting for affected sites. Finally, the operation of the whole system is evaluated with in terms of minimum cost and maximum fairness. The social benefits are the goal of relief material dispatching.

\section{Optimization Model of Collaborative Decision-Making for Emergency Relief Materials Dispatching}

Due to the limited relief materials and vehicle resources from the logistics service providers, how to distribute the relief materials to the affected areas is a key step to alleviate the suffering of affected people. Multiple stakeholders in emergency relief attempt to maximize their contribution to the relief force after large-scale disaster. However, due to the lack of collaborative decision-making mechanism, the collaborative dispatching system of relief materials has not been established. In this paper, the modeling of collaborative decision-making process involves three stages: (I) forecast the demand for emergency relief materials, which is the basis for collaborative dispatching of relief materials after disaster; (II) measure the relief emergency index of the affected areas and estimate the penalty cost of relief organizations; (III) provided that the Level-3 hub is determined, construct the "Hub-andSpoke" collaborative dispatching network to achieve the shortest distance from the affected sites to the hub and carry out collaborative dispatching of relief vehicles in Level-3 hub and affected sites.

3.1. Description of Collaborative Model for Materials Dispatching. Consider the occurrence of a large-scale disaster, e.g., an earthquake, which has caused different degrees of damage in certain affected areas that need rescue and relief supply. In order to respond to the urgent relief demands from the affected areas, this study postulates the following five assumptions to rationalize the proposed model.

(1) The number of the affected areas is known, and the geographical location of the affected area can be obtained with advanced detection technology.

(2) The relief materials are from the Front Dispatching Center, donation, or emergency purchase, and Level3 hub for emergency relief dispatching has been determined. The relief materials are delivered to the demand sites through Level-3 hub.

(3) During the critical relief period, the latest information of damages and casualties in each area 
affected by the disaster can be obtained, and the Coordination Committee would gather the information from logistics service provider and relief organization to deploy the relief actions in various demand sites.

(4) The demand will not change during the critical relief period. The relief materials with different priorities are allocated according to the demand and the emergency of the affected areas. If the relief materials cannot meet the demands of the affected area, the penalty cost will be generated. The more urgently does the affected area need the relief supply, the higher the penalty cost.

(5) There are limited vehicle resources and loading capacity of vehicles. On the basis of the above basic assumptions, the collaborative model of material dispatching in emergency relief supply chain can be used to forecast the demand for relief materials first. Then, based on the measurement of relief emergency in different affected areas and the relief emergency indexes, the Coordination Committee could assign the relief vehicles among demand points.

$$
\begin{aligned}
\min & \sum_{r} \sum_{k} C r k y_{r k t}, \\
\text { subject to } & \sum_{r} y_{r k t}=V_{k t} \cdot \forall k, t .
\end{aligned}
$$

In the objective function which aims to minimize the logistics cost of emergency relief, $C_{r k}$ is the cost for route $r$ with vehicle type $k ; y_{r k t}$ is the binary variable for selecting route $r$ and vehicle $k$ at time $t ; V_{k t}$ is the available vehicle of type $k$ in period $t$ and it is assumed that all vehicles are of the same type in this paper. The material demand is estimated at Level-3 hub, and then the relief organization collects the demand information from Level-3 hub, hoping to minimize the transportation cost.

$$
\min \sum_{i}\left(d_{i t}-x_{i t}\right) p \cdot \forall i \in I
$$

in which

$$
\begin{aligned}
x_{i t} & \leq d_{i t} \cdot \forall i, t, \\
\sum_{i} x_{i t} & \leq F_{t} \cdot \forall t, \\
\sum_{i} x_{i t} & \leq \operatorname{Cap}_{k} V_{k} .
\end{aligned}
$$

In formula (3), $p$ is the unit penalty cost for the shortage of relief materials; $x_{i t}$ is the quantity of relief materials delivered to node $i$ within time $t ; d_{i t}$ is the demand quantity at node $i$ within time $t$. The mathematical formula $\sum_{i} x_{i t} \leq F t$ represents the constraints on demand. $F_{t}$ is the quantity of relief materials that can be acquired in time $t$. $\mathrm{Cap}_{k}$ is the loading capacity of type $k$ vehicle. The overall objective function for the collaborative material dispatching in humanitarian relief supply chain is as follows:

$$
Z_{t}=\max \left\{\min _{i, r, k}\left\{w_{1}\left(d_{i t}-x_{i t}\right) p+w_{2} c_{r k} y_{r k_{t}}\right\}, 0\right\} .
$$

3.2. Material Demand Forecast in Emergency Relief. The demand forecast of relief materials is mainly divided into two categories: first, there are the daily consumptive materials, including water, food, and medicine, which will vary with time; second, there are the utilities needed by affected people, such as sleeping bags and tents. Consumable materials are mainly considered in this paper. On the basis of relevant assumptions in Section 3.1 and according to the safety stock concept, Sheu [11] proposed the demand forecast method of relief materials:

$$
D_{i}(t)=\max \left\{a^{l} \times \delta i(t) \times \bar{L}+Z_{1-\alpha} \times \operatorname{STD}_{i}(t) \times \sqrt{\bar{L}}, 0\right\}, \text { if } \in R_{\text {consm }},
$$

where $D_{i}(t)$ is the demand forecast for emergency relief materials in time $t$. $a^{l}$ represents the average hourly relief demand per survival in the affected area $i . \delta_{i}(t)$ is the estimated number of victims in the affected area $i$ in a given time. $\bar{L}$ represents the upper bound of the tolerable lead time for relief distribution to any given affected area. $R_{\text {consm }}$ denotes the daily consumables in relief activities. $\operatorname{STD}_{i}(t)$ represents the time-varying standard deviation of relief demand associated with affected area $i . z_{1-\alpha}$ represents the respective statistical value given that the tolerable possibility of time-varying relief demand shortage is $\alpha$.

3.3. Measurement of Relief Urgency in Affected Areas. The Coordination Committee shall evaluate the relief emergency of the affected areas, so as to determine the dispatching of relief materials and vehicles in Level-3 hubs and affected sites. However, researches on relief emergency are in their infancy, and relatively few studies have explored this factor. Although many scholars have considered the impact of the demand urgency on the scheduling of emergency supplies, subjective experience is used to establish the model, which lacks scientific basis. As for how to quantify the urgency of disaster demand, most scholars are inspired by the clustering idea of grouping and conduct research in a hierarchical way. The existing researches mainly have the following problems: (1) subjective experience is adopted to determine the weight combination coefficient; (2) the relevance of the indicators is ignored, and some information is calculated repeatedly; (3) the relief sequence is only based on the distance of the disaster points, while ignoring that there is a gap from the ideal plan due to the changing trend of internal factors of each disaster site. Entropy can be used to measure the degree of disorderliness of a system, which is an objective method of weight determination depending on the data of available alternatives and criteria. The weight calculation criterion of the entropy weight method is set according to the degree of numerical dispersion between indicators, which can effectively eliminate human interference and make the research 
results more objective and fair. The TOPSIS model is essentially a sorting method, and compared with the ideal solution, it is a multiobjective decision-making method. The entropy weight-TOPSIS focuses on making comprehensive evaluation by applying TOPSIS on the basis of determining the weight of each evaluation index. Therefore, the entropy weight-TOPSIS model is applied in this paper, which adopts the following steps to measure the relief emergency of the affected areas:

Step 1. Selection of evaluation indexes and matrix standardization of relief emergency.

This paper studies five indexes of emergency measure in affected areas, denoted by $C=\left\{C_{j}, j=1,2, \ldots, 5\right\}$, where $C_{1}$ refers to the casualty of affected areas; $C_{2}$ represents the population density of affected areas; $C_{3}$ refers to the proportion of vulnerable people (children and the elderly); $C_{4}$ stands for the time difference between present (i.e., Phase $t$ ) and the last times when relief materials were distributed to affected area $i$, indicated by $1-2$; and $C_{5}$ refers to the extent of damage in affected areas, indicated by $1-10$. The initial value of attribute $j$ of evaluation object $i$ is $x_{i j}$. Then, the above evaluation indicators constitute the relief emergency evaluation matrix $V$ of affected areas:

$$
V=\left|\begin{array}{cccc}
x_{11} & x_{12} & \cdots & x_{1 m} \\
x_{21} & x_{22} & \cdots & x_{2 m} \\
\vdots & \vdots & \vdots & \vdots \\
x_{i 1} & \cdots & x_{i j} & \cdots \\
\vdots & \vdots & \vdots & \vdots \\
x_{n 1} & x_{n 2} & \cdots & x_{n m}
\end{array}\right| .
$$

Since each evaluation indicator has different dimension, the decision matrix needs to be standardized. For the indicators with different properties, the processing method is also different. Among them, $r_{i j}$ is the standard value of evaluation object $j$ of indicator $i$.

For positive indicators, the following formula is adopted for standardization:

$$
r_{i j}= \begin{cases}\frac{\left[x_{i j}-\min _{j}\left(x_{i j}\right)\right]}{\left[\max _{j}\left(x_{i j}\right)-\min _{j}\left(x_{i j}\right)\right]}, & x_{j \max } \neq x_{j \min }, \\ 1, & x_{j \max }=x_{j \min } .\end{cases}
$$

For negative indicators, the following formula is adopted for standardization:

$$
r_{i j}= \begin{cases}\frac{\left[\max _{j}\left(x_{i j}\right)-x_{i j}\right]}{\left[\max _{j}\left(x_{i j}\right)-\min _{j}\left(x_{i j}\right)\right]}, & x_{j \max } \neq x_{j \min }, \\ 1, & x_{j \max }=x_{j \min } .\end{cases}
$$

For fit indicators, the following formula is adopted for standardization:

$$
r_{i j}= \begin{cases}\frac{\left[x_{i j}-\min _{j}\left(x_{i j}\right)\right]}{\left[M-\min _{j}\left(x_{i j}\right)\right]}, & x_{i \min } \leq x_{i j}<M, \\ 1, & x_{i j}=M, \\ \frac{\left[\max _{j}\left(x_{i j}\right)-x_{i j}\right]}{\left[\max _{j}\left(x_{i j}\right)-M\right]}, & M<x_{i j} \leq x_{i \max } .\end{cases}
$$

After standardization, matrix $R$ can be obtained:

$$
R=\left|\begin{array}{cccc}
r_{11} & r_{12} & \cdots & r_{1 m} \\
r_{21} & r_{22} & \cdots & r_{2 m} \\
\vdots & \vdots & \vdots & \vdots \\
r_{i 1} & \cdots & r_{i j} & \cdots \\
\vdots & \vdots & \vdots & \vdots \\
r_{n 1} & r_{n 2} & \cdots & r_{n m}
\end{array}\right| .
$$

Step 2. Determination of the weight of evaluation indicator.

The entropy method can fully reflect the degree of change of the evaluation indicator and objectively reflect the attribute of the evaluation indicator. Therefore, the weight of the evaluation indicator in this paper is determined by the entropy value $\left(H_{j}\right)$ :

$$
H_{j}=-k \sum_{i=1}^{m} p_{i j} \ln p_{i j},
$$

where $p_{i j}=r_{i j} / \sum_{i=1}^{m} r_{i j}$, when $p_{i j}=0, p_{i j} \ln p_{i j}=0 k$ is a constant, and $k=1 / \ln n$. This guarantees $0 \leq H_{j} \leq 1$.

The difference degree $\left(g_{j}\right)$ of average fixed information contained in the evaluation indicator is

$$
g_{j}=1-H_{j} \text {. }
$$

Then, the indicator weight $\left(k_{j}\right)$ is

$$
k_{j}=\frac{g_{j}}{\sum_{j=1}^{m} g_{j}} .
$$

Step 3. Construction of evaluation matrix based on entropy weight.

According to the entropy weight and indicator weight, the weighted judgment matrix is formed:

$$
Z=R B=\left|\begin{array}{cccc}
r_{11} & r_{12} & \cdots & r_{1 m} \\
r_{21} & r_{22} & \cdots & r_{2 m} \\
\vdots & \vdots & \vdots & \vdots \\
r_{i 1} & \cdots & r_{i j} & \cdots \\
\vdots & \vdots & \vdots & \vdots \\
r_{n 1} & r_{n 2} & \cdots & r_{n m}
\end{array}\right|\left|\begin{array}{cccc}
k_{1} & 0 & \cdots & 0 \\
0 & k_{2} & \cdots & 0 \\
\vdots & \vdots & \vdots & \vdots \\
0 & \cdots & k_{j} & \cdots \\
\vdots & \vdots & \vdots & \vdots \\
0 & 0 & \cdots & k_{n}
\end{array}\right|=\left|\begin{array}{cccc}
g_{11} & g_{12} & \cdots & g_{1 m} \\
g_{21} & g_{22} & \cdots & g_{2 m} \\
\vdots & \vdots & \vdots & \vdots \\
g_{i 1} & \cdots & g_{i j} & \cdots \\
\vdots & \vdots & \vdots & \vdots \\
g_{n 1} & g_{n 2} & \cdots & g_{n m}
\end{array}\right| .
$$


Step 4. Determine the difference between the affected area and the positive and negative ideal solutions.

After determining the weight of each indicator, the relief emergency of the affected area should be comprehensively evaluated. This evaluation process is based on the positive ideal solution $\left(Z^{+}\right)$and the negative ideal solution $\left(Z^{-}\right)$:

$$
\begin{aligned}
& Z^{+}=\left(\max _{i} g_{i 1}, \ldots, \max _{i} g_{i m}\right)=\left(g_{1}^{+}, \ldots, g_{m}^{+}\right), \\
& Z^{-}=\left(\min _{i} g_{i 1}, \ldots, \min _{i} g_{i n}\right)=\left(g_{1}^{-}, \ldots, g_{m}^{-}\right) .
\end{aligned}
$$

The vector $Z^{+}$is the positive ideal value of each indicator, while $Z^{-}$is the negative ideal value of each indicator. Therefore, the lengths of vector $Z^{+}$and vector $Z^{-}$are equal to the total number of indicators. Then, calculate the weighted Euclidean distance between $Z_{i}$ and $Z^{+}$and the distance between $Z_{i}$ and $Z^{-}$, respectively, as follows:

$$
\begin{aligned}
& d_{i}^{+}=\sqrt{\sum_{j=1}^{m} k_{j}\left(g_{j}^{+}-g_{i j}\right)^{2}, \quad \forall i=1, \ldots, n ; j=1, \ldots, m,} \\
& d_{i}^{-}=\sqrt{\sum_{j=1}^{m} k_{j}\left(g_{i j}-g_{j}\right)^{2}}, \quad \forall i=1, \ldots, n ; j=1, \ldots, m .
\end{aligned}
$$

Step 5. Proximity between evaluation object and ideal solution.

Calculate the relative proximity of each evaluation object to the ideal solution. This paper presents the relief emergency indicator of affected area in relative proximity (I). The bigger the indicator is, the more urgent the relief is. The specific calculation formula is

$$
I=\frac{d_{j}^{-}}{d_{j}^{+}+d_{j}^{-}} .
$$

As a result, the relief emergency of the entire affected area can be determined.

\subsection{Affected Areas Covered in Level-3 Hubs and Materials Dispatching}

3.4.1. Determination of Affected Areas Covered in Level-3 Hubs. Assume that the vehicle set is $L, L=\{1, K l, K \bar{l}\}$ and the Level-3 hub set is $J, J=\{1, K J, K \bar{J}\}$. By using the MATLAB software, the decomposition algorithm is applied to group the affected areas and allocate them to the corresponding Level-3 hub. According to the principle of covering demand points within minimum distance, the relief demand points are allocated to the corresponding three-level hub. The specific steps are as follows:

(1) Randomly select a demand point not included in any group and put it in a new group
(2) Look for the nearest demand point (not currently included in any group) to the last assigned demand point in the group and repeat the process until the predefined number of demand points in the group is met or there is no ungrouped demand point left

(3) Find the average distance of the group member from the Level-3 hubs and allocate the group to the corresponding hub according to the shortest distance principle

(4) If there is a demand point that does not belong to any group, implement Step 1

3.4.2. Dispatching of Relief Materials and Vehicles. After the affected site is allocated to corresponding Level-3 hub, how to distribute the relief materials and vehicles to the affected site with higher efficiency and lower cost is the most difficult issue that needs to be addressed in the emergency relief work. According to the demand forecast of relief materials, allocate the vehicles between Level-3 hubs based on the vehicle loading capacity, so as to realize coordinated dispatching of relief materials.

Formula (5) is used as the objective function to minimize the total transportation cost and penalty cost. It combines the targets of relief organizations and logistics service providers. $w_{1}$ and $w_{2}$ refer to the weight of penalty cost and transportation cost for relief organizations and logistics service providers, respectively. When $w_{2}=0$, it means that the logistics service providers assist the relief organizations for free.

\section{Simulation of Collaborative Decision for Emergency Dispatching of Relief Materials}

According to the Ministry of Civil Affairs of the PRC [43], there were 10 extremely severely afflicted areas and 41 severely afflicted areas in the Wenchuan Earthquake. Considering the actual situation of Sichuan, Gansu, and Shaanxi Provinces, a total of 12 affected sites are selected for investigation in the paper, including 10 counties (cities) in the extremely severely afflicted areas and 2 counties in the severely afflicted areas, they are the collaboratively distributed areas of emergency relief materials, and these sites include Wenchuan County, Beichuan County, Mianzhu City, Shifang City, Qingchuan County, Mao County, An County, Dujiangyan City, Pingwu County, Pengzhou City, Li County, Jiangyou City, and Sichuan Province.

\subsection{Demand Forecast of Relief Materials and Urgency Indicator}

4.1.1. Demand Forecast of Relief Materials. After a natural disaster such as earthquake, there could be a large number of injured people who are in urgent need of treatment; therefore, this paper mainly forecasts the demand for medical materials. The parameter of forecasting is shown in Table 2. As of May 30,2008 , the numbers of injured people in the 12 affected areas in the Wenchuan Earthquake are listed in Table 3 (data source: http://news.sohu.com/20080520/n256978695.shtml). 
TABle 2: Demand forecast of medical materials and setting of dispatching parameters.

\begin{tabular}{lc}
\hline Parameter & Values \\
\hline$a^{l}$ & 3 \\
$\bar{L}$ & $24 \mathrm{~h}$ \\
$Z_{1-\alpha}$ & 1.65 \\
$\operatorname{Cap}_{k}$ & 20000 unit \\
$\operatorname{STD}_{i}^{l}(t)$ & 10 \\
\hline
\end{tabular}

TABLe 3: Demand forecast results of medical materials in affected areas.

\begin{tabular}{lccc}
\hline Affected area & $\begin{array}{c}\text { Number of the } \\
\text { injured }\end{array}$ & Date & $\begin{array}{c}\text { Quantity demand for } \\
\text { relief materials (unit) }\end{array}$ \\
\hline Wenchuan & 34,583 & 5.29 & $2,490,057$ \\
County & 9,693 & 5.28 & 697,977 \\
Beichuan County & 31,567 & 5.20 & $2,272,905$ \\
Mianzhu City & 31,978 & 5.20 & $2,302,497$ \\
Shifang City & 15,453 & 5.29 & $1,112,697$ \\
Qingchuan & 8,183 & 5.29 & 589,257 \\
County & 13,476 & 5.20 & 970,353 \\
Mao County & 4,388 & 5.24 & 316,017 \\
An County & 32,145 & 5.20 & $2,314,521$ \\
Dujiangyan City & 5,770 & 5.24 & 415,521 \\
Pingwu County & 9,483 & 5.20 & 682,857 \\
Pengzhou City & 1,612 & 5.29 & 116,145 \\
Jiangyou City & & & \\
Li County & &
\end{tabular}

Due to difficulty in the casualty statistics and time difference of statistics, this paper only shows the number of the injured in different parts at different times from May 20 to 29. According to formula (6), the demand for medical materials is calculated, and the results are shown in Table 3.

4.1.2. Measurement of Emergency Indicator for the Affected Areas. According to the emergency evaluation indicators of the affected areas, considering the geographical locations of the affected areas, there is a time difference in dispatching. Therefore, on the basis of $C_{1}, C_{2}$, and $C_{3}$ data, the relevant data of indicator $C_{4}$ was added. However, considering the effectiveness of relief, the time difference between dispatching and relief should not be too large, and related emergency evaluation indicators are listed in Table 4.

Relevant data of the relief emergency evaluation indicators in Table 3 are used to construct the relief emergency evaluation matrix according to the principle of double base points method in the previous section. The MATLAB software is used to solve the relief emergency index of the 12 affected areas in the Wenchuan Earthquake. The results are shown in Table 5.

As can be seen from Table 5, the relief emergency of the affected areas is in the following order: Wenchuan County, Beichuan County, Mao County, Mianzhu City, Shifang City, Pengzhou City, Dujiangyan City, An County, Qingchuan County, Pingwu County, Jiangyou City, and Li County. Although the disaster information can be obtained by using advanced technology, the information is still incomplete to some extent, so the emergency degree of each area is a little different from that in actual condition. For instance, the emergency degree of Beichuan is close to that of Wenchuan, but the relief emergency index of Beichuan is only 0.3637 , significantly lower than that of Wenchuan, which is 0.8048 , because there are no other affected areas between the two counties. Therefore, the result can provide guiding to the actual relief work.

\subsection{Construction of Hub-Spoke Collaborative Dispatching Network and Material Dispatching}

\subsubsection{Construction of Hub-Spoke Collaborative Dispatching} Network. According to the emergency dispatching centers (Deyang, Mianyang, and Guangyuan) identified in the 5.12 Wenchuan Earthquake by Chen [44], since the affected areas are close to Chengdu, the Level-3 hubs for relief material dispatching are determined as four regions, including Chengdu, Deyang, Mianyang, and Guangyuan. Based on quick response of emergency relief, according to the principle that the affected areas should be covered by the Level- 3 hubs in Section 3.4, the MATLAB simulation analysis is employed to obtain the scope of the affected areas covered by the Level- 3 hubs. The results are presented in Table 6 .

The 12 affected areas covered by the Level- 3 hubs constitute the "hub-spoke" collaborative dispatching network of emergency relief materials, with the hubs as the hub and the affected areas as the spoke. See Figure 4 for the hub location type in the "hub-spoke" system.

According to the "hub" configuration principle, the hub location model of "hub-spoke" system is generally divided into "single-configuration model" and "multiple-configuration model." The collaborative dispatching network of emergency relief materials constructed in this paper is as shown in Figure 4(a), which is a single-configuration model. In such model, each node is only linked to one hub. However, in a multiple-configuration hub as shown in Figure 4(b), each node can be linked to more than one hub.

4.2.2. Dispatching of Relief Materials. According to the demand forecast of relief materials in each affected area, since the vehicles have fixed loading capacity, the collaborative dispatching of relief materials can be regarded as the dispatching of vehicles provided by logistics service providers among the Level-3 hub and demand points. Assume that the number of vehicles is limited. Based on formulas (1) and (2), in this paper, the vehicle dispatching plan with minimum transportation cost of logistics service providers and minimum penalty cost of relief organizations is formulated. According to the emergency index $I_{i}$ of the affected areas and combining the demand for relief materials, the dispatching order of the affected areas is determined. The unit penalty cost of an unmet demand at affected area is set as a fixed value of 1 , and $p$ is the product of the emergency index and unit penalty cost. The higher the emergency index is, the higher the penalty cost is.

The problem involves a multiobjective nonlinear constrained programming model, and it is NP-hard problem. In order to improve the efficiency of solution and avoid falling 
TABLE 4: Emergency evaluation indicators of the affected areas.

\begin{tabular}{|c|c|c|c|c|c|}
\hline Affected area & $\begin{array}{c}\text { Mortality (\%) } \\
C_{1}\end{array}$ & $\begin{array}{l}\text { Population density } \\
\text { (\%) } C_{2}\end{array}$ & $\begin{array}{c}\text { Vulnerable population } \\
\text { ratio }(\%) C_{3}\end{array}$ & $\begin{array}{c}\text { Time difference of } \\
\text { dispatching (hour) } C_{4}\end{array}$ & $\begin{array}{l}\text { Degree of damage of } \\
\text { buildings } C_{5}\end{array}$ \\
\hline Wenchuan County & 14.2 & 25 & 30 & 1 & 9 \\
\hline Beichuan County & 5.4 & 55 & 31 & 1 & 9 \\
\hline Mianzhu City & 2.2 & 410 & 24 & 1 & 7 \\
\hline Shifang City & 1.4 & 490 & 27 & 1 & 8 \\
\hline Qingchuan County & 1.9 & 75 & 32 & 2 & 6 \\
\hline Mao County & 3.9 & 24 & 34 & 1 & 6 \\
\hline An County & 0.3 & 353 & 27 & 2 & 6 \\
\hline Dujiangyan City & 0.5 & 502 & 26 & 1 & 8 \\
\hline Pingwu County & 0.8 & 68 & 31 & 2 & 5 \\
\hline Pengzhou City & 0.1 & 549 & 25 & 1 & 5 \\
\hline Jiangyou City & 0.05 & 144 & 26 & 2 & 5 \\
\hline Li County & 0.2 & 10 & 32 & 1 & 4 \\
\hline
\end{tabular}

TABLE 5: Relief emergency indicators of the affected areas.

\begin{tabular}{lc}
\hline Affected area & Relief emergency indicator \\
\hline Wenchuan County & 0.8048 \\
Beichuan County & 0.3637 \\
Mianzhu City & 0.2196 \\
Shifang City & 0.2107 \\
Qingchuan County & 0.1305 \\
Mao County & 0.2618 \\
An County & 0.1395 \\
Dujiangyan City & 0.1918 \\
Pingwu County & 0.0584 \\
Pengzhou City & 0.2001 \\
Jiangyou City & 0.0581 \\
Li County & 0.0103 \\
\hline
\end{tabular}

into the partial optimal solution, the simulated annealing algorithm is adopted to solve the problem. Compared with the traditional optimization algorithms, the intelligent optimization algorithm is more efficient in solving NP-hard problems. The MATLAB software is applied to achieve the minimum transportation cost. At the same time, by combining the emergency index and the demand of affected areas, the minimum penalty cost of relief organizations is calculated.

The distribution model of relief supplies is a multiobjective mixed integer linear programming model. The two objectives of minimum cost and maximum fairness in the model conflict with each other, so there is no unique solution to achieve both of them, but a set of solutions, that is, the Pareto solution, can be adopted to ensure the fairness of delivery. In order to find an effective Pareto solution to this problem, this paper devises a method to transform the multiobjective problem into multiple single-objective optimization problems. Formula (5) involves two objectives: minimum transportation cost and minimum penalty cost, and the two objectives are also in conflict with each other. There is no unique solution to achieve minimum values of both costs, so the objective function is divided into two objective functions, and the solution of model is transformed into a multiobjective optimization problem to find the Pareto optimal solution. This paper designs a simulated annealing algorithm to solve the multiobjective optimization problems. The solving steps of the model are as follows:
(1) Randomly generate an initial vehicle allocation plan that satisfies $x_{i t} \leq d_{i t}$ and $\sum_{i} x_{i t} \leq \operatorname{Cap}_{k} V_{k t}$ and calculate the transportation cost and penalty cost, respectively, as evaluation functions.

(2) Take the initial vehicle allocation plan as the Pareto optimal solution and set the initial temperature to $T_{0}$ and the maximum number of temperature drops to $K$.

(3) The original Pareto optimal solution is randomly disturbed, a new vehicle allocation plan is generated, and the new transportation cost and penalty cost are calculated, respectively. If they satisfy delta_TC_cost $\leq$ $0 \& \&$ delta_CF_cost $\leq 0 \& \&$ (delta_TC_cost $<0 \|$ delta_CF_cost $<0$ ), where delta_TC_cost $=$ transportation cost of new scheme-transportation cost of original scheme, and delta_CF_cost = penalty cost of new scheme-penalty cost of original scheme, then the new scheme is regarded as the Pareto optimal solution; otherwise, the new solution is accepted as Pareto optimal solution with a certain probability (in order to prevent the optimization problem from falling into local optimal solution).

(4) Suppose that the temperature drop function is $T=0.98 * * " T 0$. As the temperature drops, the Pareto optimal solution is continuously searched. When the temperature drops to the maximum number $K$, the Pareto optimal solution is obtained.

The results are shown in Tables 7 and 8 . When there are limited vehicles resources, the logistics service providers will prefer distributing relief materials to the disaster points with low transportation cost and higher emergency relief index. According to the results in the following table, it can be seen that, with the increase in the number of relief vehicles, the transportation cost of affected areas gradually increases, while the penalty cost gradually declines. Compared with the two types of distribution schemes to meet the needs of each affected area, it can be seen that, for transportation cost, according to the principle of shortest distance, it will choose less vehicles in order to minimize the cost, that is, by decreasing the number of vehicles. However, the demands of affected 
TABLE 6: Coverage of the Level-3 hubs.

\begin{tabular}{lc}
\hline Level-3 hub & Affected areas covered \\
\hline Chengdu & Wenchuan County, Dujiangyan City, Pengzhou City, and Li County \\
Mianyang & Beichuan County, Mao County, An County, Pingwu County, and Jiangyou City \\
Guangyuan & Qingchuan County \\
Deyang & Mianzhu City and Shifang City \\
\hline
\end{tabular}

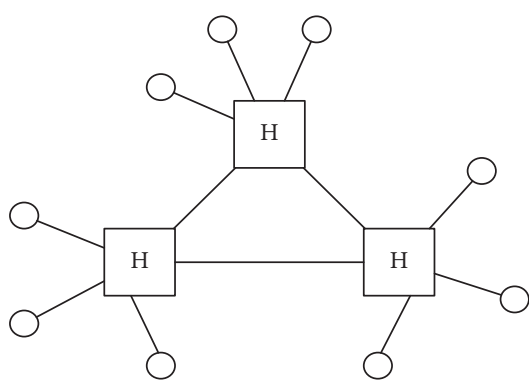

(a)

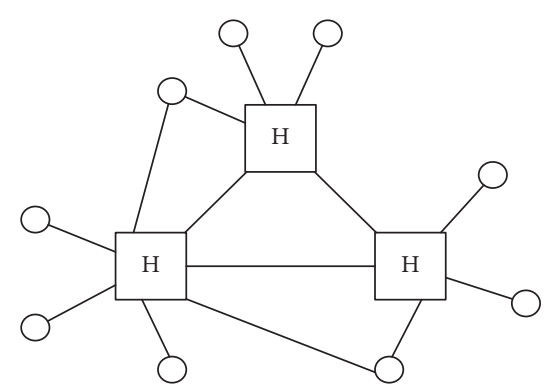

(b)

Figure 4: Hub location type in "hub-spoke" system. (a) Single-configuration model. (b) Multiple-configuration model.

TABLE 7: Vehicle allocation scheme with minimal transportation cost.

\begin{tabular}{|c|c|c|c|c|c|c|c|c|c|c|c|c|c|c|}
\hline \multirow[b]{2}{*}{ Plan } & \multirow{2}{*}{$\begin{array}{c}\text { Number } \\
\text { of } \\
\text { vehicles }\end{array}$} & \multicolumn{4}{|c|}{ Mianyang } & \multicolumn{3}{|c|}{ Deyang } & \multirow{2}{*}{$\begin{array}{l}\text { Guangyuan } \\
\text { Qingchuan }\end{array}$} & \multicolumn{4}{|c|}{ Chengdu } & \multirow[b]{2}{*}{$\begin{array}{c}\text { Transportation } \\
\text { cost }\end{array}$} \\
\hline & & Beichuan & $\begin{array}{c}\text { Mao } \\
\text { County }\end{array}$ & $\begin{array}{c}\text { An } \\
\text { County }\end{array}$ & $\begin{array}{l}\text { Ping } \\
\text { Wu }\end{array}$ & Jiangyou & Mianzhu & Shifang & & Wenchuan & Dujiangyan & Pengzhou & $\begin{array}{c}\mathrm{Li} \\
\text { County }\end{array}$ & \\
\hline 1 & 100 & 0 & 0 & 49 & 0 & 0 & 0 & 51 & 0 & 0 & 0 & 0 & 0 & $4.42 e+07$ \\
\hline 2 & 200 & 0 & 0 & 49 & 0 & 0 & 19 & 116 & 0 & 0 & 16 & 0 & 0 & $1.11 e+08$ \\
\hline 3 & 300 & 35 & 0 & 49 & 0 & 35 & 22 & 116 & 0 & 0 & 16 & 21 & 6 & $2.26 e+08$ \\
\hline 4 & 400 & 35 & 30 & 49 & 0 & 35 & 92 & 116 & 0 & 0 & 16 & 21 & 6 & $3.59 e+08$ \\
\hline 5 & 500 & 35 & 30 & 49 & 0 & 35 & 114 & 116 & 56 & 22 & 16 & 21 & 6 & $6.22 e+08$ \\
\hline 6 & 600 & 35 & 30 & 49 & 53 & 35 & 114 & 116 & 0 & 125 & 16 & 21 & 6 & $8.76 e+08$ \\
\hline 7 & 700 & 35 & 30 & 49 & 116 & 35 & 114 & 116 & 56 & 106 & 16 & 21 & 6 & $1.22 e+09$ \\
\hline
\end{tabular}

TABLE 8: Pareto optimal allocation scheme with integrated minimization of transportation cost and penalty cost.

\begin{tabular}{|c|c|c|c|c|c|c|c|c|c|c|c|c|c|c|c|}
\hline \multirow[b]{2}{*}{ Plan } & \multirow{2}{*}{$\begin{array}{c}\text { Number } \\
\text { of } \\
\text { vehicles }\end{array}$} & \multicolumn{5}{|c|}{ Mianyang } & \multicolumn{2}{|c|}{ Deyang } & \multirow{2}{*}{$\begin{array}{l}\text { Guangyuan } \\
\text { Qingchuan }\end{array}$} & \multicolumn{4}{|c|}{ Chengdu } & \multicolumn{2}{|r|}{ Cost } \\
\hline & & Beichuan & $\begin{array}{c}\text { Mao } \\
\text { county }\end{array}$ & $\begin{array}{c}\text { An } \\
\text { county }\end{array}$ & Pingwu & Jiangyou & Mianzhu & Shifang & & Wenchuan & Dujiangyan & Pengzhou & $\begin{array}{c}\mathrm{Li} \\
\text { County }\end{array}$ & $\begin{array}{c}\text { Penalty } \\
\text { cost }\end{array}$ & $\begin{array}{c}\text { Transportation } \\
\text { cost }\end{array}$ \\
\hline 1 & 100 & 9 & 0 & 22 & 0 & 0 & 0 & 52 & 0 & 17 & 0 & 0 & 0 & $1.27 e+06$ & $9.13 e+07$ \\
\hline 2 & 200 & 35 & 0 & 49 & 0 & 0 & 0 & 42 & 0 & 47 & 0 & 21 & 6 & $9.76 e+05$ & $2.49 e+08$ \\
\hline 3 & 300 & 35 & 30 & 49 & 0 & 35 & 0 & 57 & 0 & 51 & 16 & 21 & 6 & $8.30 e+05$ & $4.01 e+08$ \\
\hline 4 & 400 & 35 & 0 & 49 & 0 & 35 & 0 & 98 & 0 & 110 & 16 & 21 & 6 & $4.07 e+05$ & $5.80 e+08$ \\
\hline 5 & 500 & 35 & 30 & 49 & 0 & 35 & 38 & 116 & 56 & 98 & 16 & 21 & 6 & $3.33 e+05$ & $7.72 e+08$ \\
\hline 6 & 600 & 35 & 30 & 49 & 0 & 35 & 111 & 116 & 56 & 125 & 16 & 21 & 6 & $4.78 e+04$ & $8.94 e+08$ \\
\hline 7 & 700 & 35 & 30 & 49 & 116 & 35 & 95 & 116 & 56 & 125 & 16 & 21 & 6 & $2.32 e+04$ & $1.25 e+09$ \\
\hline
\end{tabular}

areas cannot be satisfied as a result. For example, when the number of vehicles is within the range of 100-400, no relief materials are allocated to Pingwu and Qingchuan. As the number of vehicles increases to 500 or 700 , vehicles are allocated to all affected areas, but the transportation cost is rapidly increasing.

For penalty cost, according to the emergency index of affected areas, the proposed scheme can give priority for meeting the needs of high-urgency areas in case of limited materials and realize fairness distribution to high-urgency demand points. Compared with Table 7, the dispatching of vehicles in Table 8 reflects the urgency of the demand points. When the number of vehicles is between 100 and 400, the needs of some affected areas cannot be met; but when the number of vehicles is between 500 and 700, the total periodic demand of each disaster-afflicted site can be met, and the penalty cost is further reduced. The results show that the proposed scheme can realize both minimal distribution cost and fair distribution of supplies, which breaks the limitation of traditional distribution method.

\section{Conclusion and Future Work}

This paper constructs a collaborative decision-making system for dispatching of emergency relief materials, and, based on the demand forecast of relief materials, the relief emergency of the 
affected areas is measured using the entropy-TOPSIS method, and the scope of the affected sites covered by the Level- 3 hub is also determined. In order to achieve great performance in terms of cost and fairness, the dual objectives of minimizing emergency material transportation cost and equitable distribution are considered.

The innovation of this model is to combine transportation costs with the penalty cost, and the urgency of affected areas is also considered at the same time. This can ensure that the relief supplies are delivered to as many affected areas as possible and it can also guarantee the fairness in distribution. A two-stage solving algorithm is constructed in this paper; the emergency material distribution plans are analyzed under different cost constraints and fairness distribution based on examples.

According to the conclusion, the pursuit of fair distribution of supplies will increase the number of rescue vehicles. Vehicle dispatching is a typical NP-hard problem, and it is difficult to use accurate algorithms to solve the problem of emergency materials distribution that involves a large number of affected areas. The Pareto solution can provide a variety of relief material dispatching plans to the policy-makers. The multiobjective optimization model for emergency materials distribution is proposed in this paper; the solution is limited by the scale of the problem. Therefore, a further research direction is to design an efficient method to achieve optimal solution. A static forecast optimization method is adopted in our work, and it is limited to a single category of materials. Meanwhile, the material dispatching collaboration with multiple types of materials and multiple time windows should be further investigated.

\section{Data Availability}

The data used to support the findings of this study are included within the article.

\section{Conflicts of Interest}

The authors declare no conflicts of interest.

\section{Authors' Contributions}

Gaofeng Guan conceived the outline of this study and wrote the paper. Zijun Lin, Yu Gong, and Zhijuan Jiang contributed to analysis design and provided advice for the study.

\section{Acknowledgments}

This study is supported by the National Natural Science Foundation of China (Grant no. 70771094) and Humanities and Social Sciences Fund of Ministry of Education (Grant no. 16YJA630005).

\section{References}

[1] Ministry of Emergency Management of the People's Republic of China, Basic Situation of National Natural Disasters in 2018, Ministry of Emergency Management of the People's Republic of China, Beijing, China, 2018, https://www.mem. gov.cn/xw/bndt/201901/t20190108_229817.shtml.
[2] G. Kovacs and M. Moshtari, "A roadmap for higher research quality in humanitarian operations: a methodological perspective," European Journal of Operational Research, vol. 276, no. 2, pp. 395-408, 2019.

[3] J.-B. Sheu and C. Pan, "Relief supply collaboration for emergency logistics responses to large-scale disasters," Transportmetrica A: Transport Science, vol. 11, no. 3, pp. 210-242, 2015.

[4] R. Mohammadi, S. M. T. Fatemi Ghomi, and F. Zeinali, "A new hybrid evolutionary based RBF networks method for forecasting time series: a case study of forecasting emergency supply demand time series," Engineering Applications of Artificial Intelligence, vol. 36, pp. 204-214, 2014.

[5] X. Zhu, G. Zhang, and B. Sun, "A comprehensive literature review of the demand forecasting methods of emergency resources from the perspective of artificial intelligence," Natural Hazards, vol. 97, no. 1, pp. 65-82, 2019.

[6] A. Trivedi and A. Singh, "A hybrid multi-objective decision model for emergency shelter location-relocation projects using fuzzy analytic hierarchy process and goal programming approach," International Journal of Project Management, vol. 35, no. 5, pp. 827-840, 2017.

[7] Z. Wang, H. Hu, M. Guo, and J. Gong, "Optimization of temporary debris management site selection and site service regions for enhancing postdisaster debris removal operations," Computer-Aided Civil and Infrastructure Engineering, vol. 34, no. 3, pp. 230-247, 2019.

[8] Y. Ma, W. Xu, L. Qin, and X. Zhao, "Site selection models in natural disaster shelters: a review," Sustainability, vol. 11, pp. 1-24, 2019.

[9] H. Park, D. Waddell, and A. Haghani, "Online optimization with look-ahead for freeway emergency vehicle dispatching considering availability," Transportation Research Part C: Emerging Technologies, vol. 109, pp. 95-116, 2019.

[10] M. A. Dulebenets, J. Pasha, J. Kavoosi et al., "Multi-objective optimization model for emergency evacuation planning in geographical locations with vulnerable population groups," Journal of Management in Engineering, vol. 36, no. 2, Article ID 04019043, 2020.

[11] J. B. Sheu, "An emergency logistics distribution approach for quick response to urgent relief demand in disasters," Transportation Research Part E: Logistics and Transportation Review, vol. 43, pp. 687-709, 2007.

[12] F. Wex, G. Schryen, S. Feuerriegel, and D. Neumann, "Emergency response in natural disaster management: allocation and scheduling of rescue units," European Journal of Operational Research, vol. 235, no. 3, pp. 697-708, 2014.

[13] M. Hamedi, A. Haghani, and S. Yang, "Reliable transportation of humanitarian supplies in disaster response: model and heuristic," Procedia-Social and Behavioral Sciences, vol. 54, pp. 1205-1219, 2012.

[14] M. Ahmadi, A. Seifi, and B. Tootooni, "A humanitarian logistics model for disaster relief operation considering network failure and standard relief time: a case study on San Francisco district," Transportation Research Part E: Logistics and Transportation Review, vol. 75, pp. 145-163, 2015.

[15] B. Bodaghi, E. Palaneeswaran, and B. Abbasi, "Bi-objective multi-resource scheduling problem for emergency relief operations," Production Planning \& Control, vol. 29, no. 14, pp. 1191-1206, 2018.

[16] F. Sabouhi, A. Bozorgi-Amiri, M. Moshref-Javadi, and M. Heydari, "An integrated routing and scheduling model for evacuation and commodity distribution in large-scale disaster 
relief operations: a case study," Annals of Operations Research, vol. 283, no. 1-2, pp. 643-677, 2019.

[17] Z. Ghaffari, M. M. Nasiri, A. Bozorgi-Amiri, and A. Rahbari, "Emergency supply chain scheduling problem with multiple resources in disaster relief operations," Transportmetrica A: Transport Science, vol. 16, no. 3, pp. 930-956, 2020.

[18] J. B. Sheu, "Dynamic relief-demand management for emergency logistics operations under large-scale disasters," Transportation Research Part E: Logistics and Transportation Review, vol. 46, pp. 1-17, 2010.

[19] H. Y. Pang, N. Liu, and Q. Wu, "Decision-making model for transportation and distribution of emergency relief materials and its modified particle swarm optimization algorithm," Control and Decision, vol. 27, pp. 871-875, 2012.

[20] X. Y. Song, J. G. Wang, and C. G. Chang, "Nonlinear continuous consumption emergency material Distribution problem," Journal of Systems Engineering, vol. 32, pp. 163-176, 2017.

[21] B. Zheng, Z. J. Ma, and Y. F. Zhou, "Bi-level model for dynamic location-transportation problem for post-earthquake relief distribution," Journal of Systems Management, vol. 26, pp. 326-337, 2018.

[22] B. K. Mishra, K. Dahal, and Z. Pervez, "Dual-mode RoundRobin Greedy Search with Fair Factor Algorithm for Relief Logistics Scheduling," in Proceedings of the International Conference on Information \& Communication Technologies for Disaster Management, Münster, Germany, December 2018.

[23] R. Das, "Disaster preparedness for better response: logistics perspectives," International Journal of Disaster Risk Reduction, vol. 31, pp. 153-159, 2018.

[24] K. Xue and C. Feng, "Local distribution of emergency relief materials with equity concerning," Journal of Systems Engineering, vol. 33, pp. 103-107, 2015.

[25] Y. Z. Chen and Q. H. Zhao, "The model and algorithm for emergency relief materials distribution based on fairness," Systems Engineering-Theory \& Practice, vol. 35, pp. 30653073, 2015.

[26] Y. Zhang, Y. T. Wang, and C. Feng, "Equitable dispatching models in emergency relief supplies," Chinese Journal of Systems Science, vol. 23, pp. 78-82, 2015.

[27] C. Feng, Y. Xiang, K. Xun, and R. S. Feng, "Multi-objectibe optimization model of the emergency logistics distribution with multi-cycle and multi-item," Chinese Journal of Management Science, vol. 25, pp. 124-132, 2019.

[28] J. M. Day, S. A. Melnyk, P. D. Larson, E. W. Davis, and D. C. Whybark, "Humanitarian and disaster relief supply chains: a matter of life and death," Journal of Supply Chain Management, vol. 48, no. 2, pp. 21-36, 2012.

[29] L. John, A. Gurumurthy, G. Soni, and V. Jain, "Modelling the inter-relationship between factors affecting coordination in a humanitarian supply chain: a case of Chennai flood relief," Annals of Operations Research, vol. 283, no. 1-2, pp. 1227$1258,2019$.

[30] R. Dubey, N. Altay, and C. Blome, "Swift trust and commitment: the missing links for humanitarian supply chain coordination?" Annals of Operations Research, vol. 283, no. 12, pp. 159-177, 2019.

[31] M. Naor, A. Dey, S. Meyer Goldstein, and Y. Rosen, "Civilianmilitary pooling of health care resources in Haiti: a theory of complementarities perspective," International Journal of Production Research, vol. 56, no. 21, pp. 6741-6757, 2018.

[32] R. Dubey, A. Gunasekaran, S. J. Childe et al., "Big data analytics and organizational culture as complements to swift trust and collaborative performance in the humanitarian supply chain," International Journal of Production Economics, vol. 210, pp. 120-136, 2019.

[33] R. Dubey, Z. Luo, A. Gunasekaran, S. Akter, B. T. Hazen, and M. A. Douglas, "Big data and predictive analytics in humanitarian supply chains," The International Journal of Logistics Management, vol. 29, no. 2, pp. 485-512, 2018.

[34] N. Altay and R. Pal, "Information diffusion among agents: implications for humanitarian operations," Production and Operations Management, vol. 23, no. 6, pp. 1015-1027, 2014.

[35] M. Moshtari, "Inter-organizational fit, relationship management capability, and collaborative performance within a humanitarian setting," Production and Operations Management, vol. 25, no. 9, pp. 1542-1557, 2016.

[36] R. Dubey, A. Gunasekaran, D. J. Bryde, Y. K. Dwivedi, and T. Papadopoulos, "Blockchain technology for enhancing swift-trust, collaboration and resilience within a humanitarian supply chain setting," International Journal of Production Research, vol. 58, no. 11, pp. 3381-3398, 2020.

[37] M. Eftekhar, H. Li, L. N. Van Wassenhove, and S. Webster, "The role of media exposure on coordination in the humanitarian setting," Production and Operations Management, vol. 26, no. 5, pp. 802-816, 2017.

[38] N. Altay, A. Gunasekaran, R. Dubey, and S. J. Childe, “Agility and resilience as antecedents of supply chain performance under moderating effects of organizational culture within the humanitarian setting: a dynamic capability view," Production Planning \& Control, vol. 29, no. 14, pp. 1158-1174, 2018.

[39] S. Lei, C. Chen, Y. Li, and Y. Hou, "Resilient disaster recovery logistics of distribution systems: co-optimize service restoration with repair crew and mobile power source dispatch," IEEE Transactions on Smart Grid, vol. 10, no. 6, pp. 61876202, 2019.

[40] G. Kovács and K. M. Spens, "Trends and developments in humanitarian logistics-a gap analysis," International Journal of Physical Distribution \& Logistics Management, vol. 41, no. 1, pp. 32-45, 2011.

[41] J. Bealt, J. C. Fernández Barrera, and S. A. Mansouri, "Collaborative relationships between logistics service providers and humanitarian organizations during disaster relief operations," Journal of Humanitarian Logistics and Supply Chain Management, vol. 6, no. 2, pp. 118-144, 2016.

[42] M. Vanajakumari, S. Kumar, and S. Gupta, "An integrated logistic model for predictable disasters," Production and Operations Management, vol. 25, pp. 791-811, 2016.

[43] Ministry of Civil Affairs of the PRC No. 105 Document, Notice on the Assessment Results of the Wenchuan Earthquake Disaster, Ministry of Civil Affairs, Beijing, China, 2008, http:// www.gov.cn/zwgk/2008-07/22/content_1052835.htm.

[44] G. Chen, J. Zhang, and X. Yan, "Emergency logistics distribution model for disaster relief operations," Computer Engineering and Applications, vol. 48, pp. 225-229, 2012. 